110 | Tropelías. Revista de Teoría de la Literatura y Literatura Comparada, número extraordinario 5 (2019) Álvaro Luque Amo

\title{
CORAJE DE LA VERDAD Y ESCRITURA AUTOBIOGRÁFICA EN LA MUERTE DEL PADRE DE KARL OVE KNAUSGÅRD
}

\author{
AUTOBIOGRAPHICAL WRITING AND COURAGE OF THE TRUTH \\ IN A DEATH IN THE FAMILY OF KARL OVE KNAUSGAARD
}

\author{
Álvaro LUQUE AMO \\ Universidad de Granada \\ aluqueamo@ugr.es
}

Resumen: El siguiente trabajo analiza el carácter autobiográfico de La muerte del padre, obra de Karl Ove Knausgård. Partiendo de las tesis de Manuel Alberca y Michel Foucault, se puede interpretar esta obra como un texto que se ajusta al concepto establecido por Lejeune, relacionado con el pacto pragmático entre autor y lector, para la definición de autobiografía. A ello se le añade la posibilidad de emplear la idea foucaultiana del coraje de la verdad para establecer una diferenciación entre las etiquetas de autobiografía y autoficción, que se llevará a cabo a partir del análisis de La muerte del padre.

Palabras clave: Knausgård; autobiografía; autoficción; teoría de la literatura; Foucault

Abstract: This work aims to analyze the autobiographical character of $A$ death in the Family of Karl Ove Knausgård. Starting from the theses of Manuel Alberca and Michel Foucault, this work can be interpreted as autobiography in the sense established by Philippe Lejeune, related to the pragmatic pact between author and reader. Additionally, it can determine the diference between autobiography and autofiction in the framework of the Literature of the Self.

Key words: Knausgård; Autobiography; Autofiction; Theory of Literature; Foucault 


\section{1}

\section{Marco teórico}

En los últimos años ha existido una confusión generalizada a propósito de los límites entre literatura autoficcional y literatura autobiográfica en el ámbito de los estudios literarios. Tal y como señala Ana Casas, la etiqueta de la autoficción ha sido empleada como un cajón de sastre que abarca textos como las autobiografías que utilizan formas poco habituales - como el uso de la tercera persona - o aquellas que incluyen forman paródicas; los textos autobiográficos en donde no hay identificación expresa, sino solo referida, entre autor y personaje; aquellos que presentan una voz narradora propensa a la digresión o al comentario fácilmente atribuible al autor; o incluso los relatos de autor ficcionalizado en donde se incluyen las suficientes rupturas de la verosimilitud realista como para considerarlo novela (Casas, 2012: 10-11). A esta confusión se le añade, además, la intención de algunos autores por cuestionar los cimientos de la ficción tradicional, así como por desdibujar la referencialidad de su Yo autobiográfico a través de la retórica novelística, que provoca en última instancia el cuestionamiento de la voluntad de verdad que hay en todo texto puramente autobiográfico.

En su último libro, publicado en 2017, Manuel Alberca ha esbozado una teoría de la escritura autobiográfica que intenta delimitar las fronteras entre autobiografía y autoficción y, sobre todo, denunciar los excesos de ciertas modas de la literatura actual. Manuel Alberca plantea la existencia de un tipo de texto, de carácter autobiográfico, que se construye haciendo un alarde de cierta responsabilidad autobiográfica. Alberca habla así, recurriendo a Philippe Lejeune, del concepto de antificción, en donde engloba dentro de la antificción a una serie de autores que optan por contar su vida o un episodio de esta, sin inventar nada, sin dotar a sus historias de elemento fantástico alguno. Alberca diferenciaría, por tanto, entre los autores que dejan espacio a la ambigüedad, cultivadores de la autoficción, y los que declararían su compromiso con la verdad de acuerdo a diferentes fórmulas, cultivadores de lo autobiográfico. Lo antificcional, más que un género, es empleado como un discurso que tiene "la predisposición literaria a contar la verdad y solo la verdad, que excluye radicalmente la libertad o tentación de inventar que pueden tener algunos autores de la autoficción" (Alberca, 2017: 322). La apuesta de Alberca es clara: la elección de un texto que no cae en el espacio de la incertidumbre posmoderna respecto a lo autobiográfico; un texto que, en definitiva, no necesita la muleta de la ficción pura para ser recibido y celebrado por el sistema literario.

Esta posición de Alberca puede relacionarse con la última etapa de Michel Foucault, en la cual lleva a cabo un acercamiento a las relaciones entre verdad y discurso en los textos personales de la época grecolatina. En sus últimas obras, Foucault desarrolla el concepto de parresía, que define como "la franqueza, la libertad, la apertura, que hacen que digamos lo que tengamos que decir, como nos da la gana decirlo, cuando tenemos ganas de decirlo, y en la forma como creemos necesario decirlo" (Foucault, 2005: 348). Extraído de los textos de Eurípides, en donde este le otorga un significado político, el concepto es explicado por Foucault desde dos puntos de vista: uno ético y otro técnico. 
112 Tropelías. Revista de Teoría de la Literatura y Literatura Comparada, número extraordinario 5 (2019) Álvaro Luque Amo

Desde la perspectiva ética, el concepto de parresía es muy interesante porque puede trasladar a la época clásica todas las consideraciones éticas del pacto autobiográfico de Lejeune; desde la perspectiva técnica, resulta todavía más atractivo en la medida en que Foucault lo contrapone a la retórica como modelo de hablar franco. La parresía es, en este sentido, la transmisión desnuda de la verdad misma. Este vínculo entre quien habla y lo que dice conlleva una suerte de compromiso que Foucault describe como "un pacto determinado entre el sujeto de la enunciación y el sujeto de la conducta" (2005: 380). Este pacto no es exactamente el pacto de Lejeune, porque se trata del "pacto del sujeto hablante consigo mismo" (Foucault, 2009: 81), e implica una suerte de valentía que es la de aquel que se compromete a decir la verdad por el mero hecho de ser su verdad. Para Foucault, así, la parresía “implica cierta forma de coraje, cuya forma mínima consiste en el hecho de que el parresiasta corre el riesgo de deshacer, de poner fin a la relación con el otro que, justamente, hizo posible su discurso" (Foucault, 2010: 30).

Este coraje por decir la verdad es precisamente la herramienta que empleaba Alberca para diferenciar el texto autobiográfico del autoficcional y es el elemento que, según la tesis de este artículo, puede encontrarse en La muerte del padre, obra autobiográfica de Karl Ove Knausgård. Partiendo de las tesis sobre el pacto autobiográfico de Philippe Lejeune (1994), se va a analizar en las siguientes páginas la vinculación de esta obra con las ideas de Manuel Alberca y Michel Foucault en el marco del coraje de la verdad como elemento determinante del carácter autobiográfico de ciertos textos frente a sus posibles interpretaciones autoficcionales.

\section{Estrategias autobiográficas en La muerte del padre}

\section{1. Mi lucha}

Karl Ove Knausgård ha publicado desde 2010 una saga autobiográfica que en los últimos años ha experimentado un gran éxito editorial en el contexto europeo y que puede ejemplificar la teoría expuesta. A semejanza de otras sagas autobiográficas como las Radiaciones de Jünger o el Salón de pasos perdidos de Trapiello, la obra de Knausgård posee un subtítulo que aglutina todas las entregas: "Mi lucha". El título es la primera evidencia de las relaciones entre poética autobiográfica y el coraje de la verdad foucaultiano. El sintagma "Mi lucha", que inmediatamente desvela el afán provocador de Knausgård en su cercanía con el Mein Kampf hitleriano, se puede analizar en torno a dos ejes de interpretación: Knausgård narra una lucha, la de su vida diaria, que va a permitirle construir una novela; y, al mismo tiempo, describe la confesión autobiográfica que implica desnudar su cotidianidad ante el público, lo que conlleva otra modalidad de lucha.

En el primer caso, esta lucha está perfectamente descrita en el primer tomo de la saga, La muerte del padre:

[...] cuando lo que me ha mantenido en marcha durante toda mi vida de adulto, es decir, la ambición de llegar a escribir algo grande un día, resulta amenazado de esa manera, mi único pensamiento, que me roe como una rata, es que tengo que huir. La sensación de que el tiempo se me escapa de entre los dedos mientras hago... ¿qué? Friego suelos, lavo ropa, preparo comidas, friego cacharros, hago la compra, juego con los niños en el patio, los meto en casa y los desnudo, los baño, tiendo ropa, doblo prendas y las meto en el 
armario, ordeno, friego mesas, sillas, armarios. Es una lucha, y aunque no sea heroica, la libro contra una fuerza superior (Knausgård, 2012: 42).

La lucha de Knausgård es la del escritor que, atrapado en el transcurrir de su cotidianidad, carece de tiempo para dedicarse a la profesión de escribir. Rozando la cuarentena, Knausgård intenta superar una crisis de escritura que se relaciona con su vida cotidiana; la rutina familiar no le permite encontrar tiempo para sí mismo ni, lo que le resulta más importante, para su literatura. Ante este problema, Knausgård decide encontrar una solución: la falta de tiempo para escribir la va a contrarrestar escribiendo aquello que le sucede día a día. Literaturizar su vida, pues, es el punto compensatorio al que llega Knausgård para afrontar su crisis de escritura y de vida.

Este primer elemento, la lucha cotidiana, se complementa con el segundo: la lucha consigo mismo para desnudarse en el texto y mostrar públicamente sus pensamientos de un modo descarnado y valiente, en una suerte de ejercicio terapéutico -el acto autobiográfico, de hecho, tiene un fuerte componente terapéutico-. La muerte del padre se configura como un texto elegíaco en el que Knausgård tiene el valor de desnudar sus defectos y los de su familia, reconociendo además que va a hacer literatura a partir de su privacidad y la de sus seres allegados. En un pasaje de la segunda parte del libro, el joven Knausgård acaba de escribir su primera novela, que da a leer a su hermano; la primera reacción de este es ilustrativa: "En cuanto lo terminé, a principios de junio, di el manuscrito a Yngve. Su primer comentario después de haberlo leído fue que mi padre me demandaría judicialmente. Fueron sus palabras exactas" (2012: 404).

En los siguientes puntos se va a desarrollar este pacto en relación al concepto foucaultiano del coraje de la verdad. Este pacto, no obstante, no se relaciona solo con el carácter referencial del texto; Knausgård construye toda una teoría del relato autobiográfico a partir de sus posibilidades literarias, lo que va a poner de relieve el necesario diálogo entre escritura ficcional y referencial en La muerte del padre.

\section{2. Pacto de lectura y compromiso de verdad}

En las coordenadas del pacto autobiográfico de Lejeune, Knausgård evidencia su intención de comprometerse con el lector en un pasaje de verdadera relevancia para la obra. Después de introducir a lo largo de una treintena de páginas el relato autobiográfico de su infancia, Knausgård emplea el presente para confeccionar el marco narrativo de su obra y señalar lo siguiente:

Hoy es 27 de febrero de 2008. Son las 23.43. Yo, el que escribe esto, Karl Ove Knausgård, nací en diciembre de 1968, y por tanto tengo en este momento treinta y nueve años. Tengo tres hijos, Vanja, Heidi y John, y estoy casado en segundas nupcias con Linda Boström Knausgård. Los cuatro están durmiendo en habitaciones alrededor de mí en un piso de Malmö, donde llevamos viviendo año y medio (2012: 34).

La identificación lejeuniana entre autor, narrador y personaje (Lejeune, 1994: 53) se produce en todos los niveles; Knausgård, empleando el tiempo narrativo del diario personal, se presenta a sí mismo, su familia y el espacio y el momento en el que escribe. En un párrafo, el autor es capaz de 
114 | Tropelías. Revista de Teoría de la Literatura y Literatura Comparada, número extraordinario 5 (2019) Álvaro Luque Amo

sintetizar todos los componentes del pacto de Lejeune y mostrarse ante el lector como un narrador fiel al espacio referencial vinculado a la obra. El primer rasgo de este pacto, frente al de otros pactos autobiográficos, es el carácter intradiegético del compromiso: Knausgård no firma este pacto en el prólogo, ni en ninguna otra estructura paratextual; el pacto es otro de los componentes narrativos que nutren la obra. A partir de él, el Yo autobiográfico va a someterse a un proceso de sinceridad que anuncia pocas líneas después:

Nunca digo en el fondo lo que pienso, pero siempre me acerco mucho a la persona con la que hablo, hago como si lo que me dicen me interesara, excepto cuando bebo, entonces suelo moverme demasiado lejos en dirección contraria, para luego despertarme a la angustia del exceso, que ha crecido con los años y que ahora puede durar semanas. Cuando bebo, también tengo lagunas de memoria y pierdo el control de mis actos, que suelen volverse desesperados y estúpidos, pero a veces también desesperados y peligrosos. Por eso ya no bebo. No quiero que nadie me alcance. No quiero que nadie me vea, y así ocurre: nadie me alcanza y nadie me ve. Eso debe de ser lo que se ha asentado en mi cara, lo que la ha hecho rígida y parecida a una máscara, casi imposible de asociar conmigo cuando casualmente me topo con ella en un escaparate de la calle (2012: 34-35).

El tono confesional es claro: el personaje que construye Knausgård anuncia su hipocresía en el espacio referencial, dado que el único momento de sinceridad en su vida cotidiana se relaciona con los instantes de embriaguez proporcionados por el alcohol. El resto del tiempo se comporta como un ser hipócrita; por este motivo, la confesión que cierra este pasaje de desvelamiento termina, no obstante, con una alusión a la máscara. Este pasaje y este objeto pueden interpretarse en dos direcciones: por un lado, la confesión de Knausgård acerca de su hipocresía habitual refuerza la sinceridad del texto, en la medida en que va a ser esa plataforma, el texto autobiográfico, la que compense su máscara diaria "casi imposible de asociar conmigo", señala- que ya es incapaz de corresponderse con su verdadera interioridad; por otro, la presencia de la máscara sitúa al texto en diálogo constante con el carácter literario de la narración, que inevitablemente se construye mediante diferentes superposiciones de identidad con las que Knausgård juega en todo momento. Estas últimas superposiciones serán el objeto de análisis del siguiente punto.

\section{3. El autorretrato literario}

Este juego planteado por Knausgård se ve con nitidez pocas líneas después, cuando, a partir de un tono ensayístico empleado continuamente en la obra, introduce el siguiente aforismo: "Lo único que no envejece de la cara son los ojos" (2012: 35). El motivo de los ojos, vinculado a la sinceridad de la mirada, lo conduce al célebre autorretrato de Rembrandt expuesto en la National Gallery de Londres; sobre este cuadro, Knausgård pergeña una écfrasis que le permite hilvanar una pequeña teoría de la autobiografía. Knausgård sostiene en ella que todos los elementos que definen la personalidad del autor que se pinta a sí mismo han perdido su identidad con el paso de los siglos; por el contrario, lo que queda de ese personaje pintado al óleo es su capacidad para representar con su rostro todo lo que concierne a la existencia de ser humano: 
[...] lo que está retratado, lo que Rembrandt ha pintado, es la mismísima existencia de este ser humano, esa existencia a la que despertaba cada mañana, y que enseguida se le metía dentro de los pensamientos, pero que no eran pensamientos en sí, aquello que enseguida se le metía en los sentimientos, pero que no eran sentimientos en sí, y aquello que todas las noches lo abandonaba al quedarse dormido, al final para siempre. Es esa parte del ser humano que el tiempo no toca, y aquello de lo que la luz de los ojos procede (2012: 36).

Knausgård está hablando de la universalización del arte, a la que indudablemente aspira. Si Rembrandt ha podido conseguir esa representación de lo humano a partir del sencillo retrato de su propia cara, Knausgård ambiciona algo parecido en el campo de la literatura. Este objetivo se evidencia en la conclusión de este pasaje:

La diferencia entre este cuadro y los demás cuadros tardíos pintados por Rembrandt es la diferencia entre ver y ser visto. Es decir, en este cuadro se ve a sí mismo, a la vez que él mismo es visto, y supongo que esto sólo era posible en el barroco, con su gusto por el espejo dentro del espejo, el juego dentro del juego, la puesta en escena y la fe en la conexión de todas las cosas, una época en la que la perfección artesanal alcanzó un nivel nunca logrado por nadie ni antes ni después. Pero existe en nuestro tiempo y observa por nosotros (2012: 36).

Knausgård incorpora el juego barroco de la mise en abyme para vincularlo al autorretrato literario. Este componente lúdico podría relacionar el texto con el concepto de autoficción, si bien como se verá en el último punto lo autoficcional no tiene cabida en La muerte del padre. Knausgård, más bien, está dialogando con el autorretrato literario, que Luis Beltrán Almería ha analizado en un artículo (2011) para destacar su origen pictórico y su existencia como modalidad literaria desde Cervantes. Knausgård es muy consciente de esta relación entre autorretrato y literatura autobiográfica y se propone radiografiar su vida con los mimbres del arte literario.

Muestra de esto último es la utilización de los otros dos referentes en los que Knausgård se apoya: Proust y Munch. La obra magna del primero, En busca del tiempo perdido, funciona así como la gran referencia intertextual de La muerte del padre. El personaje Knausgård confiesa la lectura obsesiva del texto de Proust cuando se muda de Noruega a Suecia y se dedica a pensar en su pasado: "por ello no sólo leía la novela En busca del tiempo perdido de Marcel Proust, sino que más o menos me la bebía" (2012: 39). La gran novela autobiográfica del siglo XX va a constituirse como el trasfondo de toda la saga autobiográfica de Knausgård; hasta tal punto es así que en la segunda parte emplea una metáfora similar a la de la célebre magdalena proustiana para explicar el desencadenante de su empresa memorialística: en este caso, una imagen en la pared con forma de rostro le hace retroceder a un episodio similar de su niñez (2012: 218-219). La diferencia respecto a Proust va a estar marcada precisamente por la segunda referencia: Munch. Al comienzo de la segunda parte de La muerte del padre, Knausgård dedica varias páginas a construir una suerte de teoría del arte en Noruega hasta llegar al anterior:

Hasta la Ilustración, el ser humano estaba subordinado a lo divino, y en el Romanticismo el ser humano estaba subordinado al paisaje en el que estaba retratado - las montañas son grandes e impetuosas, el mar es grande e impetuoso, mientras que los seres humanos, sin excepción, son pequeños-, pero en Munch es justo al revés. Es como si lo humano devorase todo, lo convirtiera todo en suyo (2012: 257). 
116 Tropelías. Revista de Teoría de la Literatura y Literatura Comparada, número extraordinario 5 (2019) Álvaro Luque Amo

En este instinto devorador se basa Knausgård para armar Mi lucha: todo el exterior está subordinado a los sentimientos y pensamientos íntimos del autor que se describe en la página. Como declaraba Susan Sontag, mientras que "en la tradición aristotélica del arte como imitación, el escritor era el medio o el vehículo para describir la verdad de algo que estaba fuera de él”, en la tradición moderna "el artista dice la verdad sobre sí mismo" (Sontag, 2014: 67). En esas coordenadas se sitúa Knausgård, quien, además, incorpora otro elemento con Munch: si el autor de El grito es el pintor más conocido del expresionismo pictórico, y su obra se caracteriza por representación hiperbólica de los sentimientos, Knausgård va a intentar plasmar precisamente esa fuerza del interior, de lo íntimo, por medio de un instrumento clave: la confesión. Así, frente al recuerdo tranquilo y sosegado de Proust, elige la desnudez descarnada de la escritura autobiográfica basada en ese coraje de la verdad. Es un autorretrato literario, como el de Proust, pero uno que se deleita especialmente en la mostración de las vísceras del Yo.

\section{4. Confesión y literatura}

La naturaleza confesional de La muerte del padre es introducida desde el comienzo del libro: las primeras páginas presentan una alegoría ensayística en la que Knausgård describe la muerte como una institución que las sociedades modernas han convertido en tabú. La muerte, en este sentido, sería el símbolo de lo privado y él, a la contra de los convencionalismos, pretende sacar a la luz todos los asuntos personales o íntimos que la sociedad encuentra faltos de decoro. Resulta curioso el hecho de que parte de la obra pictórica de Munch, precisamente, fuese confiscada por el gobierno nazi debido a su obscenidad en la representación de asuntos como la muerte. Esta, además, es el tema principal del libro, concretada en la figura del padre, cuya vida es descrita por Knausgård de una forma cruda y que se conforma como el mejor ejemplo para entender la confesión desgarradora desarrollada en la obra. $\mathrm{Su}$ padre, descrito en la primera parte de la obra como un hombre con una personalidad fuerte y reservada, sufre una vertiginosa decadencia en la última parte de su vida, años después de separarse de la madre de Karl Ove y rehacer su vida junto a Inna, con la que llega a tener una hija. Knausgård habla de la relación de su padre con Inna:

Con el tiempo dejaron el norte de Noruega para volver al sur, donde mi padre, ya gordo y seboso, y con una enorme panza, bebía sin cesar. Era impensable que se pudiera mantener sobrio unas horas para venir a buscarnos en el coche. Se divorciaron, mi padre se mudó de nuevo, esta vez a una ciudad del este donde había conseguido un nuevo trabajo que volvió a perder al cabo de unos meses, con lo que se quedó sin nada: ni matrimonio, ni trabajo, y apenas una hija, porque aunque Unni quería que él pasara tiempo con la niña, y de hecho se lo permitía, sin que por cierto saliera muy bien, con el tiempo le retiraron el derecho a las visitas, lo que a él no le importó gran cosa (2012: 276).

La vida del padre de Knausgård es descrita en estos términos hasta su muerte. En un momento dado, Knausgård llega a relatar cómo su padre, ya viviendo junto a su abuela, pasa uno o dos días con la pierna rota, en el suelo, «rodeado de platos con restos de comida, botellas y vasos con cerveza y alcohol» (2012: 277). Como señala Daniel Gascón, “impresiona que aparentemente Knausgård escriba 
lo que piensa, y el tono sincero, más íntimo que coqueto, con el que revela sus defectos, obsesiones e inseguridades" (Gascón, 2014).

A partir de la relación con su padre, el Yo protagonista desnuda además sus sentimientos en la página; la muerte del progenitor le provoca, precisamente, un llanto incontrolable que aparece repentinamente, en situaciones incómodas e inadecuadas, lo que evidencia su relación verdadera con el padre. Si bien a lo largo de la obra, el Yo de Karl Ove parece sentir odio y decepción por su padre, en la parte final se produce una suerte de anagnórisis cuando Knausgård relee su primera novela:

Levanté la cabeza. Ese libro se lo había escrito a mi padre. Yo no lo sabía, pero era así. Se lo había escrito a él. Dejé el manuscrito y me levanté. Me acerqué a la ventana. ¿Él significaba realmente tanto para mí? Pues sí, significaba tanto para mí. Yo quería que él me viera. La primera vez que comprendí que lo que escribía era realmente algo y no sólo algo que quería que fuera algo, o que fingía que era algo, fue cuando escribí un pasaje sobre mi padre y me puse a llorar mientras escribía. Era algo que jamás me había pasado. Ni por lo más remoto. Escribí sobre mi padre, y las lágrimas me chorreaban por las mejillas, apenas era capaz de ver el teclado o la pantalla. Ese dolor que se había soltado dentro de mí era algo cuya existencia desconocía. Mi padre era un idiota, alguien con quien no quería tener ningún trato, y no me costaba nada mantenerme alejado de él. No se trataba de reprimir nada, pues no había nada que reprimir, nada de él me afectaba. Así era, pero al sentarme a escribir, se me saltaron con fuerza las lágrimas (2012: 490).

Si bien la construcción narrativa es novelística, puede comprobarse cómo el tono de la narración busca en todo momento la sinceridad; el libro es una suerte de terapia en relación a la traumática relación con su padre y por ello Knausgård trata de reflejar este dolor. Por este motivo, antes se negaba la posible interpretación autoficcional; así, aunque la construcción de Karl Ove Knausgård como personaje literario protagonista de una novela es innegable, el elemento referencial que mueve los acontecimientos narrativos, así como el compromiso de su autor con la verdad de su texto, determinan su indudable naturaleza autobiográfica. Knausgård, que ya al principio de su obra reconoce -en la línea de Ricoeur- el poder narrativo de la memoria en la construcción de la identidad del sujeto, se construye a sí mismo en el texto a partir de una voluntad confesional que vincula La muerte del padre con el coraje de la verdad foucaultiano. Knausgård exhibe, por medio de una escritura parresística, la valentía de construir su personalidad privada en el texto. Esta construcción es inevitablemente literaria, pero también inevitablemente autobiográfica.

\section{Conclusiones}

Se ha podido colegir del análisis de La muerte del padre: el texto de Knausgård es un buen ejemplo de la tesis expuesta por Manuel Alberca y de las ideas del último Foucault a propósito de la autoconstitución textual del sujeto. Este coraje de la verdad, además, permite catalogar el texto de Knausgård, a pesar de su etiqueta novelística en el mercado, como un texto autobiográfico.

Tal consideración, por otro lado, no excluye la capacidad fabuladora de todo texto autobiográfico; en un artículo de Sheila Heti (2014), esta declara haberse topado con Knausgård y hacerle una pregunta de importancia. Heti, fascinada por la capacidad de Knausgård para recordar conversaciones o escenas muy precisas de su infancia, le preguntó si de verdad recordaba todo eso, a lo que este respondió: "No, me lo inventé". Knausgård demuestra con su respuesta que la sinceridad 
118 Tropelías. Revista de Teoría de la Literatura y Literatura Comparada, número extraordinario 5 (2019) Álvaro Luque Amo

construida en el texto no conlleva el carácter verídico de todo lo escrito; el coraje de la verdad no se relaciona así con una verdad científica, sino con una determinada actitud de honestidad por parte del parresiastés a la hora de narrar su vida. En una entrevista reciente, de hecho, Knausgård declara lo siguiente:

Los familiares de mi padre me acusaron de mentir. Dijeron a los medios de comunicación que no era cierto que él muriera a causa de la bebida, que había fallecido por un infarto. Me acusaron de inventarme la tremebunda descripción de esa casa para hacerme famoso a costa de las desgracias de mi familia. Fueron tantas las críticas que incluso yo empecé a dudar de mis propios recuerdos [...]. Por suerte, días después recibí una carta de una asistente social que había estado en esa casa y confirmó que mi descripción era cierta. Incluso dijo que el estado en el que se encontraba esa vivienda era peor que el que yo había detallado en el libro. Esa confirmación supuso un alivio para mí y para mi editor (Bergos, 2017).

Knausgård trabaja a partir de los materiales proporcionados por su memoria; en relación a ellos, su única garantía ante el lector se basa en una actitud honesta que deja las lagunas de recuerdo y las recreaciones narrativas en un segundo plano. Lo relevante para este trabajo no es que la escena que Heti menciona (2014) ocurriera exactamente así, sino que Knausgård mantiene ese recuerdo como una escena paradigmática de su infancia, por la cual es capaz de construir su identidad biográfica y también narrativa. En esta línea, La muerte del padre puede tener pasajes ficcionalizados y mantener ese pacto de verdad con el lector que Lejeune denomina autobiográfico.

En este sentido, se puede emplear una definición de lo autoficcional sostenida por Vera Toro para entender la verdadera idiosincrasia de la obra de Knausgård:

[...] la autoficción, según mi concepto (y el de Colonna), no se ubica en una rara zona fronteriza entre textos que por su apariencia podrían pasar por factuales (en estos casos y solo en ellos serviría de algo fijarse en indicios de ficción). Más bien se ubica en la zona de textos extremadamente ficcionales; su ficcionalidad se remata ya de por sí a través de recursos narrativos múltiples paradójicos, metaficcionales y antilusorios cuyo empleo se ubica genuinamente y necesariamente en textos ficcionales. En otras palabras: lo que abunda en una autoficción son indicios (explícitos o implícitos) de su ficcionalidad (Toro, 2017: 37).

Para Vera Toro, la autoficción se diferencia de la autobiografía porque es, a diferencia de la segunda, una ficción pura, que sencillamente recurre al Yo como uno de sus temas novelísticos. Esto no sucede en La muerte del padre, donde como se ha demostrado en este trabajo lo verdaderamente relevante, el tema central de la obra, es la actitud de un narrador que va a afrontar la verdad de su vida para hacer literatura a partir de ella. Esto es precisamente lo que lo diferencia de Proust y lo que lo asemeja a Munch: en "Mi lucha" no está el Yo que se deleita en las sensaciones poéticas y simbolistas de su pasado, sino que Karl Ove se presenta como un personaje autoconstruido a partir del grito desmesurado de su confesión vital. Se podría definir «mi lucha», así, como una suerte de expresionismo autobiográfico; una etiqueta que explica una autobiografía construida en base al coraje de la verdad. Lo que demuestra, en la línea de lo establecido por Alberca, la capacidad del concepto foucaultiano para constituirse como una herramienta teórico-literaria que aporte una gran diferenciación entre literatura autobiográfica y literatura autoficcional. 


\section{Referencias bibliográficas}

Alberca, Manuel (2017), La máscara o la vida. De la autoficción a la antificción. Málaga: Pálido Fuego.

Beltrán Almería, Luis (2011), “Diario y novela”, en Rodríguez Suárez, Luisa Paz; Pérez Chico, David (eds.), El diario como forma de escritura y pensamiento en el mundo contemporáneo, Zaragoza, Universidad de Zaragoza, pp. 9-19.

Bergos, Mónica (2017), “Karl Ove Knausgard: «Mi familia me acusa de mentir en mis libros»”, La voz de Galicia, en https://www.lavozdegalicia.es/noticia/cultura/2017/06/28/karl-ove-knausgard-familia -me-acusa-mentir-libros/0003_201706G28P38996.htm (Consulta: 10/06/2019).

Casas, Ana (2012), "El simulacro del yo: la autoficción en la narrativa actual” en A. Casas (ed.). $L a$ autoficción: reflexiones teóricas. Madrid: Arco Libros, pp. 9-42.

Foucault, Michel (2005), La hermenéutica del sujeto. Madrid: Akal.

Foucault, Michel (2009), El gobierno de sí y de los otros. Buenos Aires: Fondo de Cultura Económica.

Foucault, Michel (2010), El coraje de la verdad. Buenos Aires: Fondo de Cultura Económica.

Gascón, Daniel (2014), “El libro de la vida", Letras Libres, en https://www.letraslibres.com/mexicoespana/libros/el-libro-la-vida (Consulta: 10/06/2019).

Heti, Sheila (2014), "So Frank”, London Review of Books, en https://www.lrb.co.uk/v36/n01/sheilaheti/so-frank (Consulta: 10/06/2019).

Knausgård, Karl Ove (2012), La muerte del padre. Barcelona: Anagrama.

Lejeune, Philippe (1994), El pacto autobiográfico. Madrid: Megazul.

Sontag, Susan (2014), Contra la interpretación y otros ensayos. Barcelona: Debolsillo.

Toro, Vera (2017), Soy simultáneo: el concepto poetológico de la autoficción en la narrativa hispánica. Madrid: Iberoamericana. 